\title{
Biogeochemical Exploration at the Twin Lakes Au Deposit Using Synchrotron Radiation Micro X-ray Fluorescence and X-ray Absorption Near-edge Structure Spectroscopy
}

Zohreh Ghorbani, Juliana Casali, Chunyi Hao, Hannah Cavallin, Lisa Van Loon and Neil Banerjee

Western University, London, Ontario, Canada

The Monument Bay project, located within the Oxford-Stull Domain (OSD) of the Superior province in northeastern Manitoba, Canada, is an economically-promising Au deposit. It has 35 contiguous, un-surveyed mining claims, totalling 6,692 hectares [1]. The OSD hosts abundant lode gold deposits within shear zones of large greenstone belts [2]. The Monument Bay project has 3 main exploration targets: Twin Lakes, Mid-East, and AZ, which are located within the Stull-Wunnummin shear zone. These targets have similar geological features to other shear-hosted Archean greenstone and mesothermal gold-quartz vein deposits [3]. Various exploration techniques have been used in the study area over the past 70 years. Biogeochemical techniques have been recently employed using chemical analysis of black spruce (Picea mariana) to measure the character of underlying mineralization [4]. Although there is no one-to-one relationship in plant-substrate chemistry, clear geological relationships are still discernable within biogeochemical data. In Canada's boreal forests, black spruce is widespread and high concentrations of As and Au have been reported [4, 5]. In 1996, a beltscale multimedia geochemical survey was undertaken as part of Operation Superior [6]. The goal of sampling vegetation was to use black spruce twig chemistry to assist in mapping the concealed bedrock, which resulted in a well-constrained vegetation geochemical database. Multiple vegetation geochemical anomalies were documented from known mineralized zones at the Monument Bay property (Twin Lakes and Seeber River deposits). A positive relationship between the vegetation responses and those defined by underlying bedrock were observed [6].

\section{Experimental:}

Samples of twigs, needles, and bark were collected from live and mature black spruce located proximal and distal to the Twin Lakes Deposit. After drying, the samples were macerated and analyzed using ICP-MS. The concentration of As in plant tissues varies from 0.01 to $0.27 \mathrm{ppm}$. Samples with the highest As concentrations were prepared for X-ray absorption near-edge structure (XANES) spectroscopy at 20-BM beamline at the Advanced Photon Source, Chicago, USA. Arsenic K-edge XANES data were collected using a 500 $\mu \mathrm{m}$ focused beam over a relative energy range of $-200 \mathrm{eV}-9 \mathrm{k}$ with a dwell time of $5 \mathrm{sec}$. per point and a step size of 0.5 $\mathrm{eV}$ near the edge. XANES data were analyzed using the Athena software program [7]. Thin section offcuts prepared from half drill core samples collected at the same locations as the black spruce samples were examined using 2D synchrotron radiation micro X-ray fluorescence (SR- $\mu$ XRF) and XANES at the VESPERS beamline at the Canadian Light Source, Saskatoon, Canada. The analysis was performed directly on the samples without any special preparation. SR- $\mu$ XRF maps were collected using a $20.5 \mathrm{keV}$ pink beam and a 4element Vortex SDD. The XRF maps were collected using a $10 \mu \mathrm{m} \times 10 \mu \mathrm{m}$ spot size and a dwell time of 1 sec/point. $600 \mu \mathrm{m} \mathrm{Al}$ filters were used if necessary, to keep the detector dead time at $<25 \%$. All $\mu$ XRF data were analyzed using the Peakaboo software package [8]. Spot As XANES data was collected using mono beam: $\mathrm{Si}\left(\Delta \mathrm{E} / \mathrm{E}=10^{-4}\right)$ and an integration time of 2 secs/point.

\section{Results and Discussion:}

At the Monument Bay project, As is considered an important pathfinder element to Au mineralization, but the relationship is not yet well understood. Therefore, its distribution pattern and chemical speciation need to be evaluated within the geological context. Black spruce is able to absorb As present in soils above bedrock at depth and transfer it via its root system [4]. Therefore, black spruce tissues can integrate the geochemical signature of buried mineralization and serve as an accessible surface sampling medium for mineral exploration. 
The co-located distribution patterns of As and Fe in 2D SR- $\mu$ XRF maps are interpreted as arsenopyrite (Fig. 1a). Gold is associated with the same distribution patterns as Fe and As, confirming the utility of arsenic as an indicator of $\mathrm{Au}$ mineralization (Fig. 1b). XANES analysis of the offcut samples indicates that only $\mathrm{As}^{-1}$ is present (Fig. 2a). The preliminary results on plant samples show the predominant form of As is As ${ }^{5+}$ (Fig. 2b). No differences were observed in As speciation between the twigs, needles, and bark. This suggests that black spruce can take up As in soil released from the bedrock and stabilize it as $\mathrm{As}^{5+}$. High As concentrations may indicate locations of concealed mineralization.

\section{Conclusions:}

The ability to look at two very different substrates (plant and rocks) using the same technique with little or no sample preparation provides a direct geochemical link between them. The redox chemistry of arsenic in both As-bearing minerals and black spruce was investigated for the first time at the Monument Bay deposit. This study is of primary importance to evaluate the mechanisms of As uptake and the ability of black spruce to provide a vector to buried mineralization. With an enhanced understanding of As geochemistry transformation across the property, new exploration vectors for mineral exploration, improved mineral processing operations, and long-term environmental compliance can lead to a successful operation.

\section{Acknowledgments:}

Research described in this paper was performed at the Canadian Light Source (CLS) and Advanced Photon Source (APS). The CLS is supported by the CFI, NSERC, the Univ. of Saskatchewan, the Government of Saskatchewan, Western Economic Diversification Canada, the NRC, and the CIHR. The APS is an Office of Science User Facility operated for the U.S. Department of Energy (DOE) Office of Science by Argonne National Laboratory, and is supported by the U.S. DOE under Contract No. DE-AC02-06CH11357, and the Canadian Light Source and its funding partners. The authors acknowledge funding from NSERC and Yamana Gold Inc. We thank R. Feng, P. Blanchard, Z. Finfrock, and D. Motta Meira for support in conducting the experiments.

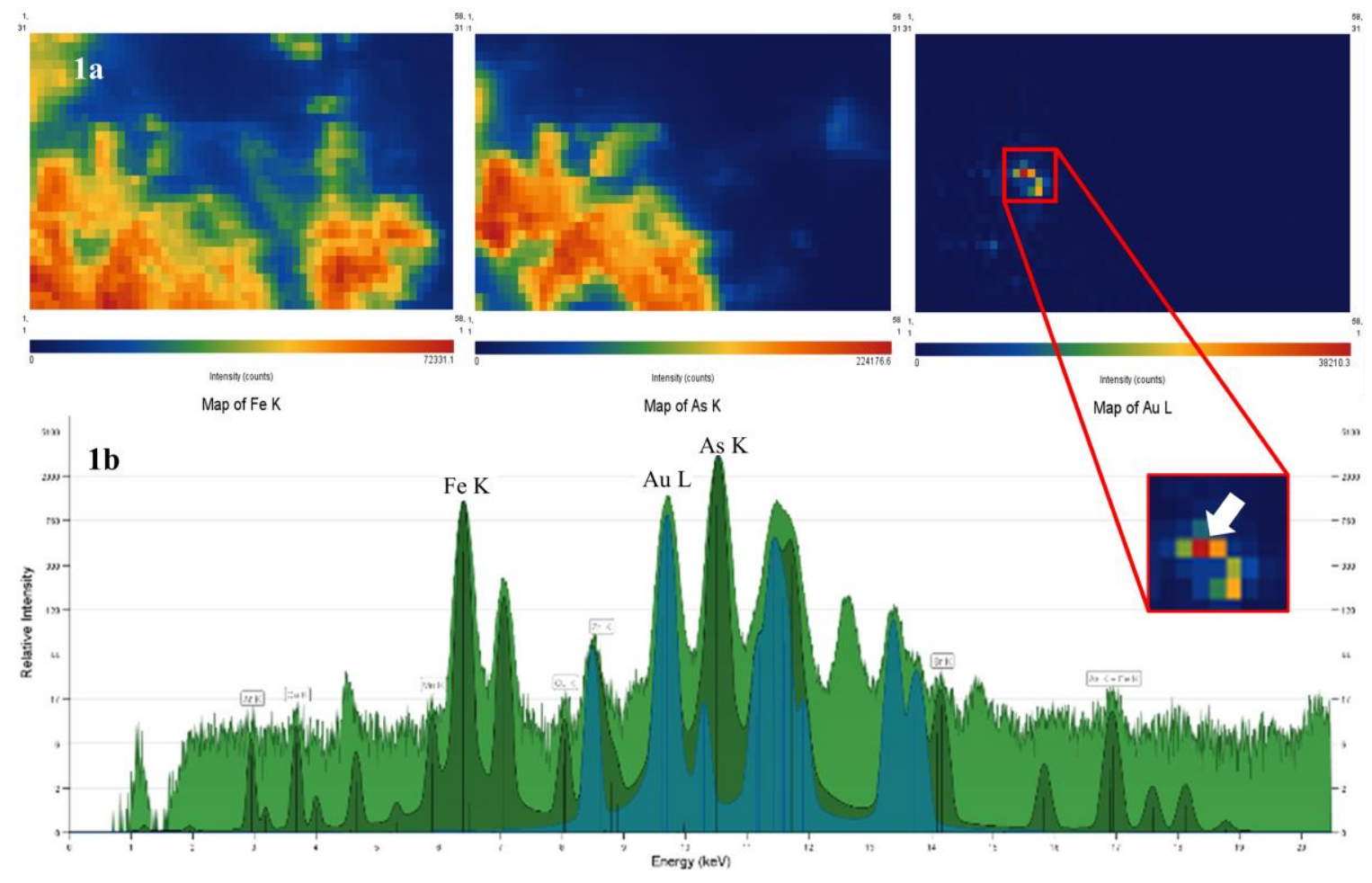


Figure 1. 1a: $2 \mathrm{D}$ element SR- $\mu$ XRF maps of Fe, As and Au. The bright regions in the Fe and As maps correspond to arsenopyrite. The red pixel in the Au map is associated with arsenopyrite. 1b: single pixel XRF MCA spectrum of the gold hotspot showing Au is associated with As and Fe.
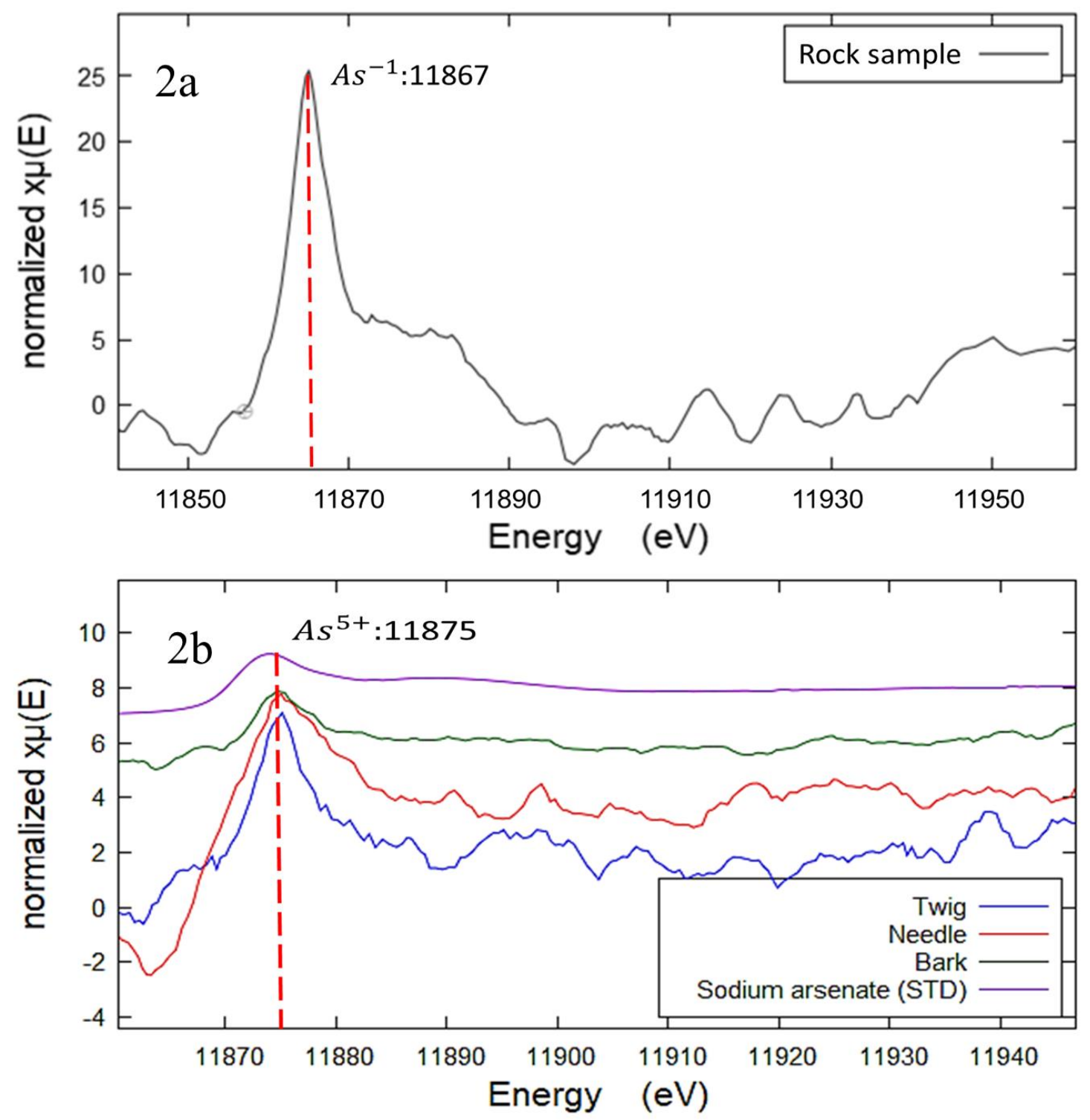

Figure 2. 2a: As K-edge $\mu$ XANES spectrum was collected at the arsenic hotspot showing arsenic oxidation form in rock samples is As-1, 2b: As K-edge XANES spectra of bark (blue), needle (red) and twig (green) collected from the same black spruce tree in comparison with sodium arsenate (purple) indicates As5+ is the dominant form.

References

1. Cavallin, H.E., et al., Application of Synchrotron Spectroscopy to Understanding Gold Mineralization at the Monument Bay Project, Stull Lake Greenstone Belt, Manitoba, Canada. Microscopy and Microanalysis, 2019. 25(S2): p. 802-803.

2. Percival, J.A., Geology and metallogeny of the Superior Province, Canada. 2007, Geological Association of Canada, Mineral Deposits Division. p. 903-928. 
3. Goldfarb, R.J. and D.I. Groves, Orogenic gold: Common or evolving fluid and metal sources through time. Lithos, 2015. 233: p. 2-26.

4. Dunn, C.E., Biogeochemistry in Mineral Exploration: Handbook of Exploration and Environmental Geochemistry Series (M. Hale, Series Editor), Volume 9. and Economic Geology, vol. 102, no. 7, 2007, pp. 1354-1354. 2007.

5. Kovalevsky, A.L., Biogeochemical Exploration for Mineral Deposits. (VNU Press, Utrecht), 224 pp. 1987.

6. Fedikow, M., et al., Operation Superior: 1996 Multimedia geochemical data from the Max Lake area (NTS 63I/8, 9 and 53L/5, 12); Manitoba Department of Energy and Mines, Mineral Resources Division, Open-File Report OF97-1, 34p. and 1 disk. 1997a.

7. Ravel, B. and M. Newville, ATHENA, ARTEMIS, HEPHAESTUS: data analysis for X-ray absorption spectroscopy using IFEFFIT. Journal of synchrotron radiation, 2005. 12(4): p. 537-541.

8. Van Loon, L.L., et al., Peakaboo: Advanced software for the interpretation of X-ray fluorescence spectra from synchrotrons and other intense X-ray sources. Software Impacts, 2019. 2: p. 100010. 